CLINICAL STUDY

\title{
TSH and free thyroxine concentrations are associated with differing metabolic markers in euthyroid subjects
}

\author{
Jose de Jesus Garduño-Garcia ${ }^{1}$, Ulices Alvirde-Garcia ${ }^{1}$, Guadalupe López-Carrasco ${ }^{2}$, Ma Elena Padilla Mendoza ${ }^{2}$, \\ Roopa Mehta ${ }^{1}$, Olimpia Arellano-Campos ${ }^{1}$, Ricardo Choza ${ }^{3}$, Leobardo Sauque ${ }^{4}$, Maria Eugenia Garay-Sevilla ${ }^{5}$, \\ Juan Manuel Malacara ${ }^{5}$, Francisco J Gomez-Perez ${ }^{1}$ and Carlos A Aguilar-Salinas ${ }^{1}$ \\ ${ }^{1}$ Departamento de Endocrinologia y Metabolismo and ${ }^{2}$ Departamento de Medicina Nuclear, Instituto Nacional de Ciencias Médicas y Nutrición Salvador \\ Zubirán, Vasco de Quiroga 15, Mexico City 14000, Mexico, ${ }^{3}$ Clinica Médica OKABE, Aguascalientes 25712, Mexico, ${ }^{4}$ Unidad Metabólica y \\ Cardiovascular Cuernavaca, Morelos 62250, Mexico and ${ }^{5}$ Instituto de Investigaciones Médicas, Universidad de Guanajuato. Leon, Guanajuato \\ 37320, Mexico \\ (Correspondence should be addressed to C A Aguilar-Salinas; Email: caguilarsalinas@yahoo.com)
}

\begin{abstract}
Objective: To examine the association between thyroid function and the components of the metabolic syndrome and insulin resistance in an Hispanic population.

Design: Cross-sectional study.

Methods: Subjects with no history of thyroid disease or diabetes were included. Thyroid function was stratified as euthyroid or subclinical hypothyroidism $(\mathrm{SCH})$ status and subsequently by free thyroxine $\left(\mathrm{FT}_{4}\right)$ and TSH tertiles. The association of the metabolic syndrome components (defined by 2004 Adult Treatment Panel III criteria) and insulin resistance with thyroid status, TSH, and $\mathrm{FT}_{4}$ were examined.

Results: A total of 3148 subjects were analyzed. The prevalence of SCH was $8.3 \%$. The prevalence of the metabolic syndrome was similar in euthyroid and $\mathrm{SCH}$ patients $(31.6 \mathrm{vs} 32.06 \%, P=0.89)$. Total cholesterol was higher in patients with $\mathrm{SCH}(5.51 \pm 1.19$ vs $5.34 \pm 1.05 \mathrm{mmol} / \mathrm{l}, P<0.032)$. Serum TSH values showed a positive correlation (adjusted for age and sex) with total cholesterol, triglycerides, and waist circumference. In contrast, $\mathrm{FT}_{4}$ showed a positive correlation with high-density lipoprotein cholesterol, and an inverse correlation with waist circumference, insulin, and HOMA-IR.

Conclusion: SCH is not associated with an increased risk for the metabolic syndrome (as conceived as a diagnostic category defined by the National Cholesterol, Education Program, Adult Treatment Panel III criteria). Despite this, low thyroid function (even in the euthyroid state) predisposes to higher cholesterol, glucose, insulin, and HOMA-IR levels. The combined use of TSH and $\mathrm{FT}_{4}$, compared with the assessment based on only $\mathrm{FT}_{4}$, is a more convenient approach to evaluate the association between thyroid function and metabolic variables.
\end{abstract}

European Journal of Endocrinology $163273-278$

\section{Introduction}

The existence of a relationship between thyroid dysfunction and cardiovascular mortality has been reported since the 1970s (1). Several studies have suggested that subclinical hypothyroidism $(\mathrm{SCH})$ increases the risk of cardiovascular disease $(2,3)$. SCH is defined as a mild elevation of TSH and normal levels of free thyroid hormones. The association between SCH and individual cardiovascular risk factors has also been explored, with discordant results (4-6). Even more controversial is the association between $\mathrm{SCH}$ and insulin resistance (7).

When exploring the relationship between thyroid function and cardiovascular risk factors, most studies have focused on the TSH levels. If free thyroxine $\left(\mathrm{FT}_{4}\right)$ levels are considered, they are generally used only to define normality. Recently, Ross and coworkers reported a significant association between $\mathrm{FT}_{4}$ levels and the components of the metabolic syndrome (MS) in euthyroid patients (8). This observation suggests that both TSH and $\mathrm{FT}_{4}$ should be considered when assessing the relationship between the metabolic syndrome traits and hypothyroidism.

Mexico has one of the highest prevalences of the metabolic syndrome, diabetes, obesity, and related diseases in the world $(9,10)$. The association of thyroid function with such diseases or syndromes has never been studied in Latin America.

The purpose of this study is to examine the association between thyroid function and the components of the metabolic syndrome and insulin resistance in an Hispanic population. 


\section{Methods}

This is a cross-sectional survey carried out in five states of central Mexico. Study subjects were recruited from the general population and employees of the government health services. The inclusion criteria included all clinically healthy adults aged between 18 and 70 years. We excluded all individuals with a history of thyroid disease: this included previously diagnosed overt hypothyroidism or hyperthyroidism, thyroid cancer or thyroid nodules, individuals with a current or past history of thyroid hormone intake, and those with a history of thyroid surgery or radioiodine intake. In the same way, individuals with diabetes, cardiovascular disease, cerebral vascular disease, amputations, pregnancy, corticosteroid use, active liver disease, and renal dysfunction, including nephrotic syndrome, were excluded.

Written informed consent was obtained from all study participants. A standardized questionnaire was applied which included questions regarding demographic information, personal and family medical history. The existence of thyroid disease was explored specifically in an eight-item section of the questionnaire. Fasting blood samples (9-12 h fast) were obtained. Anthropometric measurements were taken in a standardized manner. The blood pressure was taken using a mercury sphygmomanometer with the subjects seated for $5 \mathrm{~min}$ prior to measurement. A daily calibrated digital scale and stadimeter were used to measure body weight and height. The waist circumference was measured midway between the lower rib margin and the iliac crest in the horizontal plane with the patient standing.

All blood samples were analyzed in the laboratory of the Endocrinology and Metabolism Department of the National Institute of Medical Sciences and Nutrition, Mexico City. Analysis of the glucose and lipid samples was carried on the same day as blood sampling. Serum from each study subject was stored at $-70{ }^{\circ} \mathrm{C}$ for later analysis.

\section{Laboratory measurements}

Biochemical variables were measured using commercial kits: glucose (Glu Synchron CX, Beckman Systems, Fullerton, CA, USA), triglycerides (TG Synchron CX, Fullerton, CA, USA), high-density lipoprotein (HDL) cholesterol (HDLD Synchron CX, Fullerton, CA, USA), insulin (INSULIN Abbot AXSYM System), total cholesterol (CHOL Synchron CX, Fullerton, CA, USA), TSH (hTSH RIA-gnost, Bagnols/Cèze, France), and FT 4 (RIAgnost, Cisbio, Bagnols/Cèze, France). Low-density lipoprotein (LDL) cholesterol estimation was performed using the Friedewald formula ( $\mathrm{LDL}=$ total cholesterol (HDL - triglycerides/5)), and HOMA-IR was calculated using the following formula: (Glucose $(\mathrm{mmol} / \mathrm{l}) \times$ insulin $(\mu \mathrm{U} / \mathrm{ml})) / 22.5(11)$.

\section{Definitions}

Euthyroidism was defined as an $\mathrm{FT}_{4}$ level between 10 and $25 \mathrm{pmol} / \mathrm{l}$ with a TSH level between 0.25 and $4.5 \mathrm{mUI} / \mathrm{l}$. SCH was defined as a TSH level $\geq 4.5 \mathrm{mIU}$ and $\leq 10 \mathrm{mIU} / \mathrm{l}$, with an $\mathrm{FT}_{4}$ value between 10 and $25 \mathrm{pmol} / \mathrm{l}$. Subclinical hyperthyroidism was defined as a TSH level $\leq 0.25 \mathrm{mUI} / \mathrm{l}$ with an $\mathrm{FT}_{4}$ level between 10 and $25 \mathrm{pmol} / \mathrm{l}$. Overt hypothyroidism was defined as a TSH level $\geq 10 \mathrm{mIU} / \mathrm{l}$ independent of the $\mathrm{FT}_{4}$ value. Suppressed TSH concentrations were defined as TSH levels $\leq 0.25 \mathrm{mUI} / \mathrm{l}$.

The components of the metabolic syndrome were defined in accordance with the National Cholesterol, Education Program, Adult Treatment Panel III criteria (NCEP/ATPIII); abdominal obesity (waist circumference in men was $\geq 40$ in and in women was $\geq 35$ in), hypertriglyceridemia (triglycerides $\geq 1.7 \mathrm{mmol} / \mathrm{l}$ ), low HDL cholesterol (HDL cholesterol in men was $\leq 1.03 \mathrm{mmol} / \mathrm{l}$ and in women was $\leq 1.3 \mathrm{mmol} / \mathrm{l}$ ), elevated arterial blood pressure (blood pressure $\geq 135$ systolic and/or $\geq 85 \mathrm{mmHg}$ diastolic), and abnormal fasting glucose (blood glucose $\geq 5.6 \mathrm{mmol} / \mathrm{l}$ ). The metabolic syndrome was diagnosed in the presence of three or more of these factors.

\section{Statistical analysis}

The descriptive analysis was performed using means and S.D. for continuous variables. Qualitative variables were expressed as percentages. Means comparison was performed using the Student's $t$-test for quantitative variables with a normal distribution and with the Mann-Whitney $U$ test for those with skewed distribution. The $\chi^{2}$ test was used to compare proportions in qualitative variables. $\mathrm{FT}_{4}$ levels were stratified using tertiles: tertile I (10.00-13.51 pmol/l), tertile II $(13.52-16.72 \mathrm{pmo} / \mathrm{l})$, and tertile III (16.73-25.00 pmol/l). TSH levels were also stratified using tertiles: tertile I $(0.25-1.71 \mathrm{mU} / \mathrm{l})$, tertile II (1.72-2.68 mU/l), and tertile III (2.69-9.9 mU/l). When more than two groups were compared, ANOVA analysis was carried out with the Tukey test for normally distributed variables and Kruskal-Wallis for non-normally distributed data. The correlation of continuous variables adjusted for age and sex was calculated using multiple linear regression models. Variables with a skewed distribution were transformed to their natural logarithm to optimize the models. The association between the metabolic syndrome components and the $\mathrm{FT}_{4}$ tertiles I and III and TSH tertiles III and I was evaluated using odds ratios (OR $\pm 95 \%$ confidence interval (CI)) adjusted for age and sex with logistic regression models. Statistical tests were performed using SPSS version 12 for Windows, Chicago, IL, USA. 


\section{Results}

$\mathrm{FT}_{4}$ and TSH were measured in 3148 patients. Overt thyroid disease and suppressed TSH concentrations were found in 115 patients; these were excluded from the final analysis. Therefore, the study cohort consisted of 3033 patients, 1552 women $(51.2 \%)$ and 1481 men $(48.8 \%)$. The mean age was $42.3 \pm 10$ years, the mean body mass index (BMI) was $28.7 \pm 4.6 \mathrm{~kg} / \mathrm{m}^{2}$, and the mean waist circumference was $97.6 \pm 10 \mathrm{~cm}$. The prevalence of overweight and obesity (BMI $>25 \mathrm{~kg} / \mathrm{m}^{2}$ ) was $78.9 \%$. A BMI $>40 \mathrm{~kg} / \mathrm{m}^{2}$ was present in $1.9 \%$ of the population. The prevalence of $\mathrm{SCH}$ in the study group was $8.3 \%(7.1 \%$ of men and $10.1 \%$ of women, $P=0.004)$. The mean TSH level was $2.49 \pm 1.42 \mathrm{mU} / \mathrm{l}$, and the mean $\mathrm{FT}_{4}$ was $15.43 \pm 3.64 \mathrm{pmol} / \mathrm{l}$.

\section{SCH and the metabolic syndrome}

The prevalence of the metabolic syndrome was similar in euthyroid and SCH subjects, 31.6 vs $32.06 \%$ $(P=0.89)$ respectively. The prevalence of the components was also similar in both groups (Table 1).

There was no significant difference in the mean values for each of the components of the metabolic syndrome and insulin resistance surrogate markers in euthyroid and SCH subjects (Table 2). Only total cholesterol was significantly higher in $\mathrm{SCH}$ subjects compared with euthyroid participants $(5.51 \pm 1.19$ vs $5.34 \pm 1.05 \mathrm{mmol} / \mathrm{l}, \quad P<0.032$ respectively). The OR for hypercholesterolemia (defined as total cholesterol $>5.2 \mathrm{mmol} / \mathrm{l}$ ), when adjusted for age and sex in SCH subjects was 1.35 (95\% CI 1.06-1.70), $P<0.034$.

\section{Associations between the metabolic variables and TSH and $\mathrm{FT}_{4}$ concentrations in the total study sample}

Serum TSH values showed a positive correlation (adjusted for age and sex) with total cholesterol, LDL cholesterol, triglycerides, waist circumference, systolic blood pressure, insulin, and HOMA-IR (Table 3). When adjusted for BMI, age, and gender, the correlation remained significant for triglycerides $(\beta=0.077$, $P<0.001)$ and total cholesterol $(\beta=0.070, P>0.001)$.

Table 1 Prevalence of the MS components in euthyroid and subclinical hypothyroidism (SCH) subjects.

\begin{tabular}{lccc}
\hline $\begin{array}{l}\text { Metabolic syndrome } \\
\text { components }\end{array}$ & $\begin{array}{c}\text { Euthyroid } \\
(n=2771)\end{array}$ & $\begin{array}{c}\text { SCH } \\
(n=262)\end{array}$ & $\boldsymbol{P}$ value \\
\hline Low HDL cholesterol (\%) & 60.8 & 59.9 & 0.780 \\
Abnormal fasting glucose (\%) & 12.4 & 13.7 & 0.534 \\
Hypertriglyceridemia (\%) & 56.8 & 55.7 & 0.743 \\
Abdominal obesity (\%) & 42.9 & 42.4 & 0.853 \\
High blood pressure (\%) & 26.4 & 28.5 & 0.524 \\
\hline
\end{tabular}

${ }^{*}$ Comparison of proportions calculated by $\chi^{2}$ test.
Table 2 Components of the MS and markers of insulin resistance in euthyroid and subclinical hypothyroidism $(\mathrm{SCH})$ subjects. Data are expressed as means.

\begin{tabular}{|c|c|c|c|}
\hline Variables & $\begin{array}{l}\text { Euthyroid } \\
(n=2771)\end{array}$ & $\begin{array}{c}\text { SCH } \\
(n=262)\end{array}$ & $P$ value \\
\hline Weight (kg) & $75.4 \pm 14.7$ & $74.2 \pm 15.46$ & 0.914 \\
\hline BMI $\left(\mathrm{kg} / \mathrm{m}^{2}\right)$ & $28.69 \pm 4.5$ & $28.98 \pm 5.1$ & 0.459 \\
\hline Waist (in) & $37.09 \pm 4.4$ & $37.03 \pm 4.4$ & 0.839 \\
\hline $\begin{array}{l}\text { Systolic blood } \\
\text { pressure }(\mathrm{mmHg})\end{array}$ & $115 \pm 15.12$ & $118 \pm 16.23$ & 0.210 \\
\hline $\begin{array}{l}\text { Diastolic blood } \\
\text { pressure }(\mathrm{mmHg})\end{array}$ & $77.29 \pm 10.68$ & $78.22 \pm 10.87$ & 0.617 \\
\hline Glucose $(\mathrm{mmol} / \mathrm{l})$ & $4.90 \pm 1.16$ & $4.91 \pm 0.973$ & 0.570 \\
\hline Triglycerides (mmol/l) & $2.29 \pm 1.73$ & $2.59 \pm 4.03$ & 0.397 \\
\hline $\begin{array}{l}\text { Total cholesterol } \\
(\mathrm{mmol} / \mathrm{l})\end{array}$ & $5.34 \pm 1.05$ & $5.51 \pm 1.19$ & 0.032 \\
\hline HDL cholesterol $(\mathrm{mmol} / \mathrm{l})$ & $1.10 \pm 0.29$ & $1.13 \pm 0.29$ & 0.460 \\
\hline LDL cholesterol $(\mathrm{mmol} / \mathrm{l})$ & $3.22 \pm 0.82$ & $3.34 \pm 0.95$ & 0.182 \\
\hline Insulin (pmol/l) & $71 \pm 46.11$ & $79 \pm 46.11$ & 0.103 \\
\hline HOMA-IR & $2.6 \overline{7} \pm 2.0$ & $3.05 \pm 3.0$ & 0.266 \\
\hline
\end{tabular}

$P$ value calculated using the Student's $t$-test for normally distributed variables and the Mann-Whitney $U$ test for variables with a skewed distribution.

In general, $\mathrm{FT}_{4}$ showed similar correlations as those found for TSH. However, some differences should be mentioned. $\mathrm{FT}_{4}$ had a positive correlation with $\mathrm{HDL}$ cholesterol, and an inverse correlation with waist circumference, glycemia, insulin, and HOMA-IR. When adjusted for BMI, age, and gender, the correlation remained significant for insulin $(\beta=-0.099$, $P<0.001)$, HOMA-IR $(\beta=-0.107, P<0.001)$, and HDL cholesterol $(\beta=0.093, P<0.001)$.

Fasting insulin and HOMA-IR changed significantly between $\mathrm{FT}_{4}$ tertiles; the lower the $\mathrm{FT}_{4}$ level, the higher the fasting insulin (tertile I $80 \pm 49 \mathrm{pmol} / \mathrm{l}$, tertile II $72 \pm 48 \mathrm{pmol} / \mathrm{l}$, and tertile III $64 \pm 42 \mathrm{pmol} / \mathrm{l}$, $P<0.001$ ) and HOMA-IR (tertile I $2.99 \pm 2.08$, tertile II $2.70 \pm 2.27$, tertile III $2.39 \pm 1.91, P<0.001$ ) values. This phenomenon is not seen between TSH tertiles and insulin (tertile I $72.32 \pm 48.70 \mathrm{pmol} / \mathrm{l}$, tertile II 70.84 $\pm 44.51 \mathrm{pmol} / \mathrm{l}$, and tertile III $75.03 \pm 49.75 \mathrm{pmol} / \mathrm{l}$, $P=0.108$ ) or HOMA-IR values (tertile I $2.68 \pm 2.1$, tertile II $2.60 \pm 1.8$, and tertile III $2.74 \pm 2.34, P=0.85$ ). In a multivariate regression model, the relationship of $\mathrm{FT}_{4}$ with HOMA-IR $(\beta=-0.107, P<0.001)$ and insulin $(\beta=-0.096, P<0.001)$ remained significant after adjusting for sex, BMI, age, and TSH values. The same is true for the relationship between TSH and total cholesterol $(\beta=0.75, P<0.001)$ and triglycerides ( $\beta=0.77, P<0.001)$ after adjusting for sex, BMI, age, and $\mathrm{FT}_{4}$ values.

The agreement between the TSH and $\mathrm{FT}_{4}$ tertiles was moderate $(\kappa 0.71)$. The individuals in the highest TSH tertile were not the same as those with the lowest $\mathrm{FT}_{4}$ levels. This feature allowed us to carry out a separate analysis exploring the effect of $\mathrm{FT}_{4}$ and TSH on several metabolic variables. We compared HOMA-IR and fasting insulin values between $\mathrm{FT}_{4}$ tertiles in the third of the population with the highest TSH values (tertile III). 
Table 3 Correlation of the components of the MS and markers of insulin resistance with levels of free thyroxine $\left(\mathrm{FT}_{4}\right)$ and $\mathrm{TSH}$ adjusted for age and sex.

\begin{tabular}{lrrrrr}
\hline & \multicolumn{2}{c}{ TSH } & & \multicolumn{2}{c}{ Free T $_{\mathbf{4}}$} \\
\cline { 2 - 3 } \cline { 6 - 6 } & \multicolumn{1}{c}{$\beta$} & \multicolumn{1}{c}{$P$} & & \multicolumn{1}{c}{$\beta$} & \multicolumn{1}{c}{$P$} \\
\hline Total cholesterol & 0.070 & $<0.001$ & -0.049 & 0.006 \\
LDL cholesterol & 0.059 & 0.003 & -0.044 & 0.029 \\
HDL cholesterol & -0.027 & 0.120 & & 0.099 & $<0.001$ \\
Triglycerides & 0.084 & $<0.001$ & & -0.033 & 0.053 \\
Waist circumference & 0.104 & $<0.001$ & -0.129 & $<0.001$ \\
Systolic pressure & 0.014 & 0.015 & -0.049 & 0.009 \\
Diastolic pressure & 0.026 & 0.174 & -0.026 & 0.179 \\
Fasting glucose & 0.005 & 0.775 & -0.059 & 0.010 \\
Insulin & 0.045 & 0.016 & -0.169 & $<0.001$ \\
HOMA-IR & 0.038 & 0.046 & -0.181 & $<0.001$ \\
\hline
\end{tabular}

Values of $\beta$ are standardized regression coefficients calculated by linear regression models adjusted for age and gender.

Patients with the lowest $\mathrm{FT}_{4}$ values (tertile I) had higher HOMA-IR $(3.05 \pm 2.1$ vs $2.7 \pm 3.4, P<0.001)$ and insulin values compared with cases in the second and third $\mathrm{FT}_{4}$ tertiles $(81 \pm 49$ vs $71 \pm 49 \mathrm{pmol} / \mathrm{l}$, $P<0.001)$. No difference was observed in cholesterol and triglycerides concentrations between $\mathrm{FT}_{4}$ tertiles. We repeated this analytical process, this time evaluating the effect of variations in TSH levels (classified by tertiles) on HOMA-IR and insulin in subjects with the lowest $\mathrm{FT}_{4}$ concentrations (tertile I). Patients with the highest TSH values (tertile III) had higher cholesterol concentrations compared with cases in the first and second TSH tertiles $(5.4 \pm 1.07$ vs $5.2 \pm 1.05 \mathrm{mmol} / \mathrm{l}$, $P<0.001)$. No differences were observed in HOMA-IR, insulin, and triglycerides concentrations between TSH tertiles. These data suggest that TSH and $\mathrm{FT}_{4}$ provide complementary information with respect to the effects of thyroid hormones on lipid and carbohydrate metabolism. Insulin resistance is associated with low $\mathrm{FT}_{4}$ but not high TSH values. In contrast, LDL cholesterol concentrations are higher in cases with high TSH concentrations.

\section{Associations between the metabolic variables and TSH and TT $_{4}$ concentrations in euthyroid subjects}

In order to assess whether the above-described associations are valid in normal conditions, we repeated the analysis excluding SCH patients. After adjusting for age, gender, and BMI, the association of $\mathrm{FT}_{4}$ with $\mathrm{HDL}$ cholesterol, fasting insulin, and HOMA-IR remained significant (HDL $\beta=0.068, P<0.0001$; fasting insulin $\beta=-0.099, \quad P<0.0001$; HOMA-IR $\beta=-0.107$, $P<0.0001)$. The association of TSH with total cholesterol and triglycerides also remained significant (total cholesterol $\beta=0.071, P<0.0001$ and triglycerides $\beta=0.09, P<0.0001)$. In a multivariate regression model, the relationship of $\mathrm{FT}_{4}$ with HOMA-IR $(\beta=-0.105, P<0.001)$ and insulin $(\beta=-0.097$,
$P<0.001)$ remained significant after adjusting for sex, BMI, age, and TSH values. The same is true for the relationship between TSH and total cholesterol $(\beta=0.63, \quad P<0.001)$ and triglycerides $(\beta=0.97$, $P<0.001)$ after adjusting for sex, BMI, age, and $\mathrm{FT}_{4}$ values.

\section{Discussion}

In this study, we explore the relationship between thyroid function and the components of the metabolic syndrome and markers of insulin resistance in an Hispanic population. The study sample consisted of individuals with no history of thyroid disease or diabetes and a high prevalence of obesity. Individuals with SCH as compared with euthyroid persons had a higher prevalence of hypercholesterolemia. No other difference was encountered between these groups with respect to the components of the metabolic syndrome and insulin resistance markers. As a result, $\mathrm{SCH}$ cannot be considered a risk factor for the metabolic syndrome. Despite these findings, $\mathrm{FT}_{4}$ concentrations showed a negative correlation with waist circumference, fasting insulin, and HOMA-IR and a positive correlation with HDL cholesterol. TSH values, on the other hand, showed a positive correlation (adjusted for age and gender) with total cholesterol, triglycerides, and waist circumference. The relationship between the insulin resistance markers and plasma lipids with $\mathrm{FT}_{4}$ and TSH levels can be appreciated even if only euthyroid patients are considered. Therefore, the concentration of thyroid hormones appears to influence insulin action and lipoprotein metabolism even in the euthyroid state.

Several studies have looked into the possibility of an association between the metabolic syndrome and SCH (12). Two small studies $(13,14)$ reported that $\mathrm{SCH}$ is a risk factor for the metabolic syndrome (as defined by the International Diabetes Federation). Our data do not confirm this conclusion. The prevalence of the metabolic syndrome (defined using the NCEP/ATPIII criteria) was no different between cases with or without SCH. Our results are in agreement with data published by Kim and coworkers (15). Reasons for the discrepancy among studies include differing criteria used to define the metabolic syndrome and dissimilar sample size and characteristics of the populations under study. The lack of association between SCH and the metabolic syndrome may result from the differential effect that hypothyroidism has on the various components of the metabolic syndrome. $\mathrm{FT}_{4}$ showed a positive correlation with HDL cholesterol, and an inverse correlation with waist circumference, systolic blood pressure, glycemia, insulin, and HOMA-IR. However, when the confounding effect of obesity (assessed using the BMI) was controlled, only one component of the metabolic syndrome (i.e. HDL cholesterol levels) remained significantly associated. Other metabolic variables independently associated with either $\mathrm{FT}_{4}$ or TSH values 
(i.e. HOMA-IR, insulin, and LDL cholesterol) are not included in the definition of the metabolic syndrome. Our report in contrast to others does not confirm an association between SCH and the metabolic syndrome. This is probably because the confounding effect of obesity was controlled for in the statistical analyses, and a high proportion of persons with obesity were included in both the cases and control groups.

The association between hypercholesterolemia and overt or SCH is well established (16-18). $\mathrm{T}_{4}$ is required for the expression of the LDL receptor gene (19). In our study, there was a significant association between SCH and hypercholesterolemia. In addition, in euthyroid individuals, TSH concentrations were strongly associated with total cholesterol and LDL cholesterol levels. The association between LDL cholesterol and $\mathrm{FT}_{4}$ was less strong and lost statistical significance after controlling for age, gender, and BMI. We propose that TSH is a better indicator because both LDL cholesterol (through the LDL receptor gene) and TSH levels are strongly determined by tri-iodothyronine-mediated regulation of gene expression. In contrast, the association between $\mathrm{FT}_{4}$ and $\mathrm{LDL}$ cholesterol is influenced by prereceptor, tissue-specific events that modulate the hormonal message.

On the other hand, thyroid hormones influence carbohydrate metabolism, even in the euthyroid state. They regulate hepatic gluconeogenesis, lipogenesis, and lipolysis. Also, thyroid hormones modulate mRNA and protein expression of the glucose transporter 4, AMPactivated protein kinase, and acetyl CoA carboxylase in skeletal muscle (20). Despite the known actions of thyroid hormones on carbohydrate metabolism, in vivo studies carried out in humans have provided inconclusive results. Stephan et al. determined insulin sensitivity (based on the hyperinsulinemic-euglycemic clamps) in 46 euthyroid patients (21). No correlation was found between both $\mathrm{TSH}$ or $\mathrm{FT}_{4}$ values and insulin sensitivity. In contrast, in this study, we observed a highly significant association between fasting insulin and HOMA-IR values and $\mathrm{FT}_{4}$. Differences in sample size between studies and varying methods for the measurement of insulin may explain the divergent results. The larger sample size of our study may have allowed us to find a significant correlation between $\mathrm{FT}_{4}$ levels, HOMA-IR, and fasting insulin levels, despite the use of an indirect method for measuring insulin sensitivity. $\mathrm{FT}_{4}$ had a stronger association with the insulin resistance markers than TSH. The multiple direct and indirect ways by which thyroid hormones regulate carbohydrate metabolism may explain this observation (20, 22). Thus, $\mathrm{FT}_{4}$ and TSH provide complementary information for the evaluation of the effects of thyroid hormones on carbohydrate and lipoprotein metabolism.

One limitation of this study is the cross-sectional design. As a result, a cause-effect relationship cannot be established. Furthermore, we did not include thyroid autoantibodies in our assessment. Their inclusion may have been helpful to confirm the existence of a thyroid disorder in cases with high TSH values. This remark is particularly important in individuals with morbid obesity, a condition in which raised serum levels of TSH may be independent of thyroid function (23).

In summary, this report extends the existing information about the association between the components of the metabolic syndrome and thyroid function in both $\mathrm{SCH}$ and the euthyroid state. Our data show that $\mathrm{SCH}$ is not associated with an increased risk for the metabolic syndrome (as conceived as a diagnostic category defined by the NCEP/ATPIII criteria). Despite this, low thyroid function (even in the euthyroid state) predisposes to higher cholesterol, glucose, insulin, and HOMA-IR levels. The combined use of $\mathrm{TSH}$ and $\mathrm{FT}_{4}$ is a more convenient approach, compared with the assessment of only $\mathrm{FT}_{4}$, to evaluate the associations between thyroid function and metabolic variables.

\section{Declaration of interest}

The authors declare that there is no conflict of interest that could be perceived as prejudicing the impartiality of the research reported.

\section{Funding}

This research did not receive any specific grant from any funding agency in the public, commercial, or not-for-profit sector.

\section{Author contribution statement}

J de J Garduño-Garcia wrote manuscript, researched data, U AlvirdeGarcia researched data, G López-Carrasco researched data, M E Padilla Mendoza researched data, R Mehta contributed to discussion, reviewed/edited manuscript, O Arellano-Campos researched data, R Choza researched data, L Sauque researched data, M E Garay-Sevilla researched data, reviewed/edited manuscript, J M Malacara researched data, reviewed/edited manuscript, F J Gomez-Perez researched data, reviewed/edited manuscript, and C A Aguilar-Salinas researched data, reviewed/edited manuscript.

\section{Acknowledgements}

The authors express their gratitude to Socorro Romero Figueroa PhD (Universidad Autonoma del Estado de México) for her careful review of the study protocol. No potential conflicts of interest relevant to this article are reported.

\section{References}

1 Heinonen O, Aho K, Pyörälä K, Gordin A, Punsar S \& Puro K. Symptomless autoimmune thyroiditis in coronary heart disease. Lancet 19718 785-786.

2 Ochs N, Auer R, Bauer DC, Nanchen D, Gussekloo J, Cornuz J \& Rodondi N. Meta-analysis: subclinical thyroid dysfunction and the risk for coronary heart disease and mortality. Annals of Internal Medicine $2008 \mathbf{1 4 8} 832-845$.

3 Rodondi N, Aujesky D, Vittinghoff E, Cornuz J \& Bauer DC. Subclinical hypothyroidism and the risk of coronary heart disease: a meta-analysis. American Journal of Medicine 2006119 541-551. 
4 Takashima N, Niwa Y, Mannami T, Tomoike H \& Iwai N. Characterization of subclinical thyroid dysfunction from cardiovascular and metabolic viewpoints: the Suita study. Circulation Journal 2007 71 191-195.

5 Luboshitsky R, Aviv A, Herer P \& Lavie L. Risk factors for cardiovascular disease in women with subclinical hypothyroidism. Thyroid $200212421-425$.

6 Hueston WJ \& Pearson WS. Subclinical hypothyroidism and the risk of hypercholesterolemia. Annals of Family Medicine 20042 351-355.

7 Tuzcu A, Bahçeci M, Gokalp D, Tuzun Y \& Gunes K. Subclinical hypothyroidism may be associated with elevated high-sensitive C-reactive protein (low grade inflammation) and fasting hyperinsulinemia. Endocrine Journal 200352 89-94.

8 Ross A, Stephan J, Bakker L, Links TP, Gans R \& Wollfenbuttel HR. Thyroid function is associated with components of the metabolic syndrome in subjects eutiroid. Journal of Clinical Endocrinology and Metabolism 200792 491-496.

9 Cameron AJ, Shaw JE \& Zimmet PZ. The metabolic syndrome: prevalence in worldwide populations. Endocrinology and Metabolism Clinics of North America 200433 351-375.

10 Córdova-Villalobos JA, Barriguete-Meléndez JA, Lara-Esqueda A, Barquera S, Rosas-Peralta M, Hernández-Avila M, León-May ME \& Aguilar-Salinas CA. Chronic non-communicable diseases in Mexico: epidemiologic synopsis and integral prevention. Salud Pública de México $2008 \mathbf{5 0} 419-427$.

11 Matthews DR, Hosker JP, Rudenski AS, Naylor BA, Treacher DF \& Turner RC. Homeostasis model assessment: insulin resistance and beta cell function from fasting plasma glucose and insulin concentrations in man. Diabetología 198528 412-419.

12 Biondi B \& Cooper D. The clinical significance of subclinical thyroid dysfunction. Endocrine Reviews 200829 76-131.

13 Demidova TIu \& Galieva OR. The role of thyroid hypofunction in development of metabolic syndrome. Endocrine Journal $2007 \mathbf{5 4}$ $71-76$.

14 Uzunlulu M, Yorulmaz E \& Oguz A. Prevalence of subclinical hypothyroidism in patients with metabolic syndrome. Terapevticheskii Arkhiv 200981 69-73.
15 Kim B, Kim TK, Koh JM, Kim HK, Park JY, Lee KU, Shong YK \& Kim WB. Relationship between serum free $\mathrm{T}_{4}\left(\mathrm{FT}_{4}\right)$ levels and metabolic syndrome and its components in healthy euthyroid subjects. Clinical Endocrinology 2009 70 152-160.

16 Cannaris GJ, Manowitz NR, Mayor G \& Ridgway EC. The Colorado thyroid disease prevalence study. Archives of Internal Medicine 2000 $160526-534$.

17 Lindeman R, Schale DS, LaRue A, Romero LJ, Liang HC, Baumgratner RN, Koheler KM \& Garry PJ. Subclinical hypothyroidism in a biethnic, urban community. Journal of the American Geriatrics Society 199947 703-709.

18 Walsh JP, Bremner AP, Bulsara MK, O'Leary P, Leedman PJ, Feedema $\mathrm{P} \&$ Michelangeli V. Thyroid dysfunction and serum lipids: a community-based study. Clinical Endocrinology 200563 670-675.

19 Duntas LH. Thyroid disease and lipids. Thyroid 200212 287-293.

20 Crunkhorn S \& Patti ME. Links between thyroid hormone action, oxidative metabolism, and diabetes risk? Thyroid $2008 \mathbf{1 8}$ 227-237.

21 Stephan JL, Bakker JC, Maaten CP, Joris PJ, Heine RJ \& Gans RO. The relationship between thyrotropin and low density lipoprotein cholesterol, is modified by insulin sensitivity in healthy euthyroid subjects. Journal of Clinical Endocrinology and Metabolism 200186 1206-1211.

22 Maratou E, Hadjidakis DJ, Kollias A, Tsegka K, Peppa M, Alevizaki M, Mitrou P, Lambadiari V, Boutati E, Nikzas D, Tountas N, Economopoulos T, Raptis SA \& Dimitriadis G. Studies of insulin resistance in patients with clinical and subclinical hypothyroidism. European Journal of Endocrinology $2009 \mathbf{1 6 0}$ 785-790.

23 Rotondi M, Leporati P, La Manna A, Pirali B, Mondello T, Fonte R, Magri F \& Chiovato L. Raised serum TSH levels in patients with morbid obesity: is it enough to diagnose subclinical hypothyroidism? European Journal of Endocrinology $2009160403-408$.

Received 13 May 2010

Accepted 1 June 2010 